\title{
Contextualização e complexidades temporais: um exercício a partir da narrativa jornalística
}

Contextualization and temporal complexities: an exercise from journalistic narrative

Contextualización y complejidades temporales: un ejercicio desde la narrativa periodística

DOI: https://doi.org/10.1590/1809-5844202123

\section{Carlos Alberto Carvalho ${ }^{1}$}

https://orcid.org/0000-0001-8433-8794

\section{Bruno Souza Leal ${ }^{1}$}

http://orcid.org/0000-0002-6937-6976

\section{Phellipy Pereira Jácome ${ }^{1}$}

http://orcid.org/0000-0001-6939-7542

${ }^{1}$ (Universidade Federal de Minas Gerais, Faculdade de Filosofia e Ciências Humanas, Programa de PósGraduação em Comunicação Social. Belo Horizonte - MG, Brasil).

\section{Resumo}

O objetivo deste trabalho é discutir os processos de contextualização como ferramenta metodológica nas análises de narrativas jornalísticas. Nesse sentido, recupera-se, do ponto de vista teórico, uma discussão sobre o "contexto", buscando considerar as complexas redes temporais nas relações textuais. Em seguida, propõe-se um gesto analítico a partir das diferentes formas de contextualizar uma imagem fotográfica nas páginas de um jornal impresso. Como metodologia, adotamos a seleção de uma página do jornal O Estado de S. Paulo, que contém uma fotografia vencedora do Prêmio Esso, cotejando com outras fotografias jornalísticas, investigando-as como situadas em contextos específicos, mas também como elas próprias são agentes de contextualização.

Palavras-chave: contexto. historicidades. temporalidade. jornalismo. narrativa.

\begin{abstract}
The aim of this paper is to discuss the contextualization processes as a methodological tool in the analysis of journalistic narratives. In this sense, a discussion about the "context" is recovered from the theoretical point of view, seeking to consider the complex temporal networks in textual relations. Then, an analytical gesture is proposed based on the different ways of contextualizing a photographic image on the pages of a printed newspaper. As a methodology, we adopted the selection of a page of the newspaper O Estado de S. Paulo, which contains an Esso Award-winning photograph, collating
\end{abstract}


with other journalistic photographs, investigating them as situated in specific contexts, but also as themselves contextualizing agents.

Keywords: context. historicities. temporality. journalism. narrative.

\section{Resumen}

El objetivo de este trabajo es discutir los procesos de contextualización como una herramienta metodológica en el análisis de narrativas periodísticas. En este sentido, se recupera una discusión sobre el "contexto" desde el punto de vista teórico, buscando considerar las complejas redes temporales en las relaciones textuales. Luego, se propone un gesto analítico basado en las diferentes formas de contextualizar una imagen fotográfica en las páginas de un periódico impreso. Como metodología, adoptamos la selección de una página del periódico O Estado de S. Paulo, que contiene una fotografía ganadora del Premio Esso, cotejando con otras fotografías periodísticas, investigándolas como situadas en contextos específicos, pero también como agentes contextualizadores.

Palabras clave: contexto. historicidades. temporalidad. periodismo. narrativa.

\section{Introdução}

Recentemente, um conjunto de pesquisadores brasileiros (LEAL; CARVALHO, 2017, RIBEIRO; MARTINS; ANTUNES, 2017, REGO; BARBOSA, 2017, MANNA; JÁCOME, FERREIRA, 2017, entre outros) chamaram a atenção para a necessidade de se atentar para as relações que envolvem a contextualização como um gesto metodológico. Em comum, esses trabalhos apontam para a necessidade de “desnaturalizar o contexto" e deixar de entendê-lo como um "exterior”, uma espécie de pano de fundo do texto e/ou fenômeno comunicacional. Apoiando-se ora nos estudos da linguagem, ora na história, afirmam a instabilidade fundamental do contexto e para os movimentos implicados nos processos de contextualização. Assim, por exemplo, Ribeiro, Martins e Antunes (2017) afirmam, por um lado, que se as textualidades midiáticas se materializam num processo incessante de abrir e fechar fronteiras, texto e contexto não deveriam significar polos opostos ou estabilizados. Por outro, entendem que

Falar em construção do real no discurso não significa assumir, portanto, necessariamente uma posição idealista. Significa simplesmente negar qualquer tipo de separação estanque entre a linguagem e a sua exterioridade constitutiva. E é nesse sentido - enquanto exterioridade constitutiva - que entendemos o conceito de contexto, tema de nossa reflexão. Contexto não é pano de fundo; não é uma dimensão externa aos fenômenos e que com eles estabelece uma relação causal. [...] Não existe uma realidade prévia a algum tipo de enunciação, já que (repetindo) as instâncias material e discursiva são engendradas em um único e mesmo processo. (RIBEIRO; MARTINS; ANTUNES, 2017, p. 8). 
Ao afirmar a não existência de uma “realidade prévia” à enunciação, os autores não estão certamente desprezando os componentes histórico-sociais que conformam uma dada situação social e comunicacional. Estão, parece-nos, afirmando a potência produtiva presente em cada ato comunicativo, que não é simplesmente determinado pelas circunstâncias prévias, uma vez que age sobre elas e abre possibilidades mais ou menos amplas de sentido, significação e referencialidade. Nesse sentido, como propõe Ricoeur (2006), a vida é um relato à espera de narrador, o que inclui um mundo prefigurado do qual qualquer trama é parte, ao mesmo tempo em que reconhece a abertura tornada possível pelo próprio ato de narrar e configurar uma inteligibilidade cognoscível, refigurada pelo choque entre o mundo do texto e o mundo do leitor.

Todo ato narrativo, desse modo, pressupõe algum nível de alteração semântica, fruto de processos de sedimentação e de inovação. Tais processos, é importante frisar seguindo as pistas de Ricoeur (2006), sugerem que os contextos do mundo prefigurado são instabilizados precisamente pela ação de leitura, que não somente é contextualmente situada em tempos e lugares específicos, como é ela própria uma modalidade de contextualização. Uma narrativa literária, histórica ou jornalística, portanto, está eternamente aberta a leituras que a situem interpretativamente para além de sentidos originalmente propostos. Consequentemente, cada gesto de leitura está imerso em contextos variados, relacionados aos mundos do texto e de quem lê, numa multiplicidade de realidades culturais, acionamentos de memórias, mas também esquecimentos.

É exatamente essa flutuação propositiva e atuante que permite que Manna, Jácome e Ferreira (2017) e Jácome (2020) apontem, por sua vez, para as variações de sentido e referencialidade que a expressão “jornalismo” apresenta em alguns momentos históricos brasileiros. Nessa perspectiva, o exercício de caracterizar as relações que um fenômeno, um texto midiático qualquer, estabelece com um momento histórico se torna mais complexo. “Contextualizar” não é simplesmente posicionar, às vezes sem muita dificuldade, os objetos da comunicação em um fundo histórico estável, supostamente dado, ou uma determinada cronologia linear, em que se indicam a sucessão ou a simultaneidade de acontecimentos. Ao contrário, fazem-se necessários movimentos analíticos desafiadores, de modo a perceber como os fenômenos comunicacionais atuam no mundo, como são “...atravessados e convocam distintas temporalidades que constituem” (RIBEIRO; MARTINS; ANTUNES, 2017, p. 15), num gesto reflexivo que põe em questão também as temporalidades de quem pesquisa, de quem se aproxima desses processos e fenômenos. Nesse sentido, essa proposta se afasta do "contexto" ou da "contextualização” como um atributo específico de um conjunto particular de narrativas, como podemos perceber, por exemplo, no diagnóstico realizado por Fink e Schudson (2013) acerca do que avaliam ser um giro contextual do jornalismo estadunidense na segunda metade do século XX. Propomos aqui, por um lado, que, metodologicamente, os gestos de pesquisa são desafiados pelas tramas temporais que “contextualizam” os fenômenos e processos comunicacionais, e, por outro, que métodos, 
teorias e visões de mundo de quem pesquisa são também parte constitutiva dos contextos e das estratégias de inteligibilidade acionadas.

Uma outra abordagem das variantes temporais presentes na contextualização é encontrada em Leal e Carvalho (2017), que explicitam as instabilidades de passados, presentes e futuros nas articulações entre contexto, acontecimento e narrativa. Recusando também a ideia de contexto como algo estável, como pano de fundo externo ao fenômeno comunicacional, os autores, retomando diferentes perspectivas teóricas, observam um "chamado à contextualização" que buscaria respeitar o agir humano, a "experiência de mobilidade fundamental do trajeto humano e das múltiplas dimensões temporais, de presentes, passados e futuros, que permeiam nossas vidas”. Contextualizar seria assim um esforço de apreender ao menos parte dessas "inter-relações”, que se apresentam “em constante rearticulação” (LEAL; CARVALHO, 2017, p. 8). Novamente, o cuidado metodológico implícito nesse “chamado à contextualização” está na problematização do próprio tempo da observadora ou do observador, das temporalidades que atravessam quem contextualiza, cujo olhar pode optar - perversa ou inocentemente, mas por certo equivocadamente - por estabilizar (no passado, no presente ou no futuro) relações em constante transformação.

$\mathrm{O}$ artigo que aqui apresentamos tem como pressuposto esse conjunto de temas e perspectivas que sintetizamos muito rapidamente. A proposta é a de um exercício de contextualização, que visa ao mesmo tempo respeitar e explorar diferentes variáveis temporais articuladas a uma imagem fotográfica específica, publicada em uma típica página de jornal impresso, num período de crença em um possível novo projeto político-social e de consolidação democrática para o Brasil. Ao longo do percurso argumentativo deste artigo buscamos caracterizar algumas das relações que atravessam e que instabilizam, a nosso ver, significações, sentidos e referências dessa fotografia, a partir da mudança do olhar dos pesquisadores. Nesse exercício analítico, os processos de contextualização da imagem fotográfica mobilizados expõem, a nosso ver, as complexidades temporais presentes tanto nas textualidades jornalísticas quanto nos modos como nos aproximamos delas.

Metodologicamente, nos valemos de outras fotografias jornalísticas além daquela capturada na página do jornal impresso com o objetivo de melhor situar os desafios metodológicos e conceituais implicados nas noções de contexto. Em parte, as fotografias têm em comum terem sido vencedoras do Prêmio Esso ou expressarem relações de gênero pautadas pelo machismo e pela misoginia. Todas elas, por outro lado, foram produzidas para complementação de narrativas jornalísticas que têm a política como acontecimento em foco.

\section{Uma contextualização espacial}

A imagem fotográfica abaixo, de autoria de Wilton Sousa Junior, foi publicada em 21 de agosto de 2012, no jornal O Estado de S.Paulo, sendo reproduzida também no seu site de notícias. Como se vê, ela apresenta a presidenta Dilma Rousseff olhando e se inclinando 
para baixo, como que atravessada por uma espada, empunhada por um militar (numa relação metonímica com o braço, a luva e a mão), a partir dos modos como a cena foi composta.

\section{Figura 1 -}

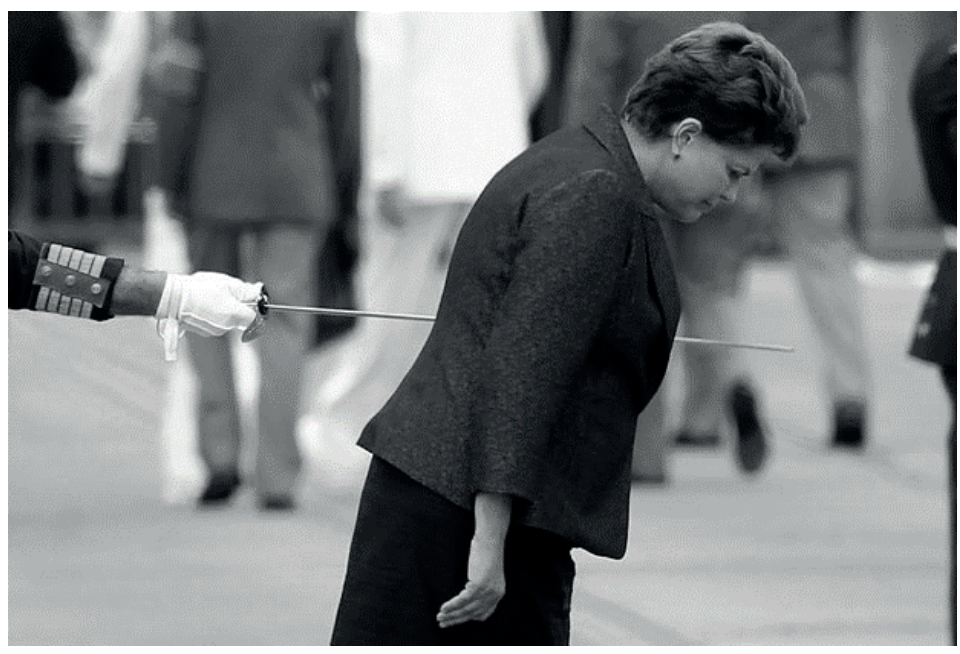

Fonte: https://www.estadao.com.br.

De que fala essa fotografia? Não se trata, por certo, do flagrante de um atentado à então presidenta da República. Não sendo um texto visual de sentido literal, a fotografia, em razão do jogo composicional que materializa, desafia qualquer esforço rápido de significação e referencialidade, instigando nossa compreensão e abrindo-se a diferentes caminhos para sua contextualização. A simples conjectura se a imagem é literal ou não já ilustra os desafios presentes nos processos de contextualização, ou seja, de caracterização de relações de sentido, de significação e referencialidade de um dado texto ou fenômeno. Afinal, a literalidade não é uma condição óbvia ou intrínseca da unidade textual, dependendo de um conjunto de repertórios de quem lê, que, necessariamente, evoca referências do passado (imediato ou mais distante) e mesmo do presente em torno do "aqui agora" da leitura. Esse movimento de contextualização é, então, o de posicionar um dado texto ou fragmento textual num conjunto de relações que o perpassam e no qual ele atua, condicionando e modulando expectativas, repertórios e articulações.

Um primeiro movimento possível de contextualizar essa imagem fotográfica envolve observar a posição que ela ocupa na página do jornal, no invólucro sensível de um formato que a constrange e a relaciona com outros textos verbovisuais (MOURA, 2020, LEAL; JÁCOME, 2020) Apartada dessas unidades textuais, a imagem fotográfica permanece um tanto enigmática, provocadora, e é certo que adquiriria sentidos diversos caso o conjunto textual que a cerca fosse outro. Como podemos perceber na Figura 2, a fotografia faz parte da página A7, do caderno "Nacional” do jornal O Estado de S. Paulo. Caso se tratasse de uma imagem literal, de uma suposta agressão à presidenta, ela não seria certamente nem tão 
pequena nem ocuparia as páginas centrais de um jornal impresso, indo diretamente à capa. Ali, ela funciona simultaneamente como uma tradicional foto-legenda, inclusive com título próprio ("Honras militares”), e como ilustração de uma narrativa jornalística ("Desconfiado de Dilma, PMDB faz planos para 2014”.), textualidades que retomaremos abaixo.

\section{Figura 2 -}

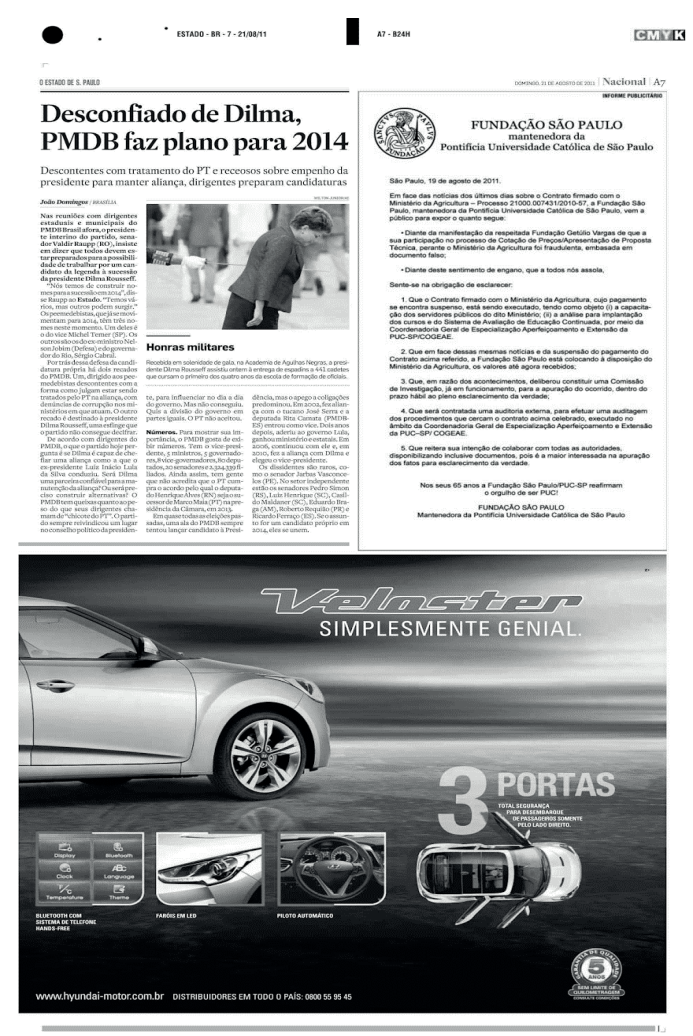

Fonte: https://www.estadao.com.br.

Na página apresentada na Figura 2, a composição verbovisual se complementa com dois anúncios publicitários, um institucional, da Fundação São Paulo, mantenedora da Pontifícia Universidade Católica de São Paulo, e outro que anuncia um automóvel da marca Hyundai. Embora não mantenham relação imediata com o conteúdo da narrativa política envolvendo a presidenta Dilma Rousseff, as publicidades remetem a sentidos presentes na realidade brasileira, de longa data, ou indicando condições de consumo mais específicas dos governos do PT. No primeiro caso, a Fundação presta esclarecimentos sobre contrato firmado com o Ministério da Agricultura, afirmando a sua legalidade, indicando o velho problema da corrupção como componente da realidade brasileira, tema, aliás, genericamente referido na narrativa sobre os descontentamentos do PMDB com Dilma Rousseff, informado 
no texto que ocupa o quarto superior esquerdo da página. O anúncio do automóvel, por sua vez, nos permite associações com a expansão do consumo dessa modalidade de bens duráveis verificado especialmente a partir do segundo mandato de Luiz Inácio Lula da Silva, que beneficiou amplos segmentos da classe média.

A página do jornal rapidamente oferece-se, então, como um primeiro espaço para que algumas dessas relações de contextualização se efetivem. Mais especificamente em seu conteúdo jornalístico, na legenda que acompanha a foto, temos a informação de que a fotografia se refere a uma cerimônia de formatura na Academia das Agulhas Negras, que envolveu a entrega de espadas aos formandos. $\mathrm{O}$ olhar e a inclinação da presidenta correspondem, então, ao seu movimento de descida do palco da cerimônia e uma reverência demonstrada a outra autoridade. Esse primeiro texto, porém, se situa a foto num passado e a princípio a cola a um referente específico, é cercado de um outro, bem maior, que fala dos conflitos entre a bancada de políticos do então PMDB e a presidenta, indicando inclusive a possibilidade de ruptura da aliança de governo, com o potencial lançamento de candidatura própria, pelo partido, nas eleições de 2014. Como sabemos, essa ameaça não se concretizou no processo eleitoral e o partido manteve Michel Temer como vice-presidente. No entanto, a ruptura se deu no percurso do segundo mandato de Dilma Rousseff, culminando em seu questionável impedimento.

$\mathrm{Na}$ articulação entre os textos verbais e o texto visual, assim, um curioso jogo de sentidos e referencialidades se estabelecem. Por um lado, se a legenda indica a redução do campo de significações da imagem fotográfica, a narrativa noticiosa volta a ampliálo. O título informativo que anuncia a fotografia, "honras militares”, também se abre a múltiplos significados, positivos (de homenagem, seja da presidenta aos formandos, seja destes à presidenta), ou negativos (um possível e mortal descontentamento dos militares com Dilma Rousseff). O posicionamento da fotografia no canto direito da notícia, abaixo do título que promove a união entre essas unidades informativas, sugere que aquela é uma ilustração da notícia “Desconfiado de Dilma, PMDB faz planos para 2014”. Trata-se então de um caso interessante de encaixe narrativo, em que o texto visual e a legenda que o acompanha, apesar de se referirem a outro acontecimento - a formatura - estão encaixados numa narrativa principal - a da disputa política - à qual conferem outras dimensões de sentido, sobretudo quando analisadas agora, no "futuro" daquela imagem. Nesse sentido, um gesto de contextualização é capaz de ver naquele presente, relações temporais mais amplas que envolvem tanto uma mobilização do passado quanto uma ação prenhe de futuro. Como aponta Santos (2016, p. 1), na interpretação de uma imagem estamos concomitantemente diante de uma história "acolhida” e de uma história "adivinhada”.

\section{Uma contextualização na história}

A foto da presidenta Dilma Rousseff, de autoria de Wilton de Sousa Júnior, foi vencedora do Prêmio Esso de Jornalismo de 2012, sob a denominação “Touché”. O Prêmio 
é referência do que se convencionou como reconhecimento pelo trabalho jornalístico que se distingue pela qualidade, distribuído em diversas categorias, como reportagem e fotografia, no impresso, além daquelas destinadas ao rádio, à televisão e à internet. Produzir uma imagem informativa competitiva para o Prêmio, não raro, constitui objetivo de fotojornalistas, o que exige atenção a detalhes e à composição da cena, perspicácia para o potencial informativo e agilidade para a captura de um “bom flagrante”. Pressupõe-se, portanto, que para merecer o Prêmio, a fotografia deve conter mais do que a informação aparente, sendo capaz de acionar sentidos polissêmicos, provocar emoções, sensibilizar para um drama individual ou social, dentre outras variáveis. São, quase sempre, fotografias que "entram para a história” como paradigmáticas de um tempo, de personagens, de um “contexto”.

Personagens do mundo político flagrados em alguma situação inusitada não raro constituem o foco de fotografias vencedoras do Prêmio Esso, como a produzida por Enro Scheneider, que levou a premiação em 1961 (Figura 3). Nela, o ex-presidente Jânio Quadros aparece com as pernas em posições diferentes quanto a que rumo caminhar, como uma metáfora das indecisões que marcaram sua curta passagem pela presidência da República, à qual ele renunciou sob a alegação de dificuldades impostas por supostas “forças ocultas”. Lida retrospectivamente, a fotografia indica, para além da errância política de Jânio Quadros no momento do flagrante, a própria instabilidade política brasileira dos anos 1960, que levaria ao golpe civil-militar de 1964 .

\section{Figura 3 -}

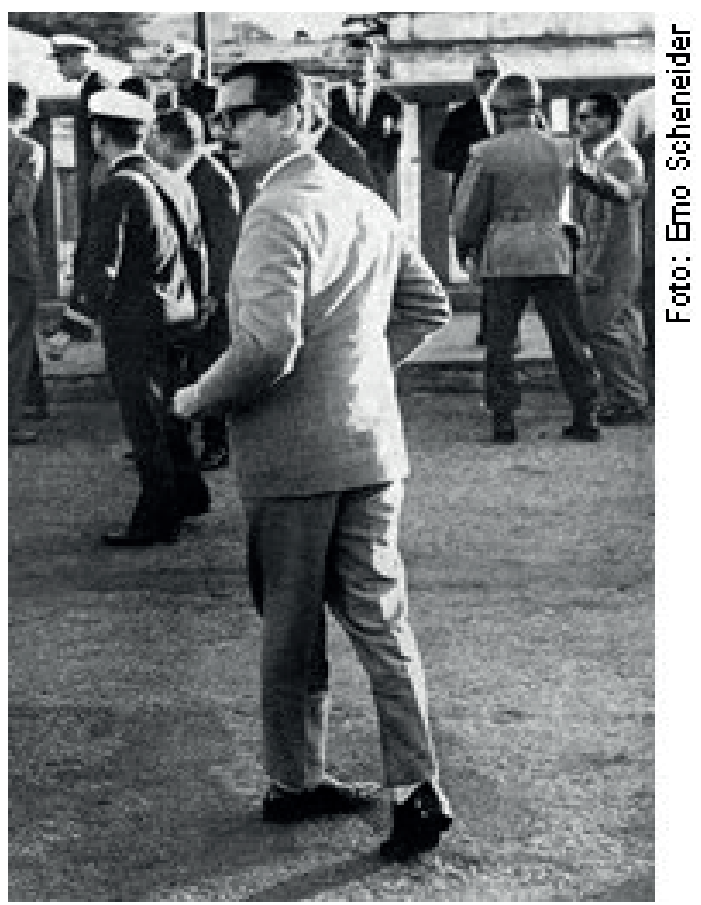

Fonte: https:/www12.senado.leg.br/noticias/materias/2011/08/25/janio-uma-foto-que-interpretou-a-historia. 
Fotografias não vencedoras do Prêmio Esso também se destacam na história política brasileira por se situarem no lado oposto da captura perspicaz de um flagrante, pois resultam da pose combinada entre determinada personagem e quem fotografa. É o caso do também ex-presidente Fernando Henrique Cardoso sentado na cadeira de prefeito de São Paulo, um dia antes do processo eleitoral de 1985, capturada pelo fotógrafo Reginaldo Manente (Figura 4). Fernando Henrique alega que havia um acordo de publicação somente se o resultado das eleições lhe fosse favorável, pacto não cumprido pelo jornal Folha de S.Paulo, que estampou a foto na sua primeira página antes do supostamente combinado. Para além de qualquer explicação, a fotografia passou à história política brasileira como sinônimo de arrogância e de descuido com as dinâmicas eleitorais.

\section{Figura 4 -}

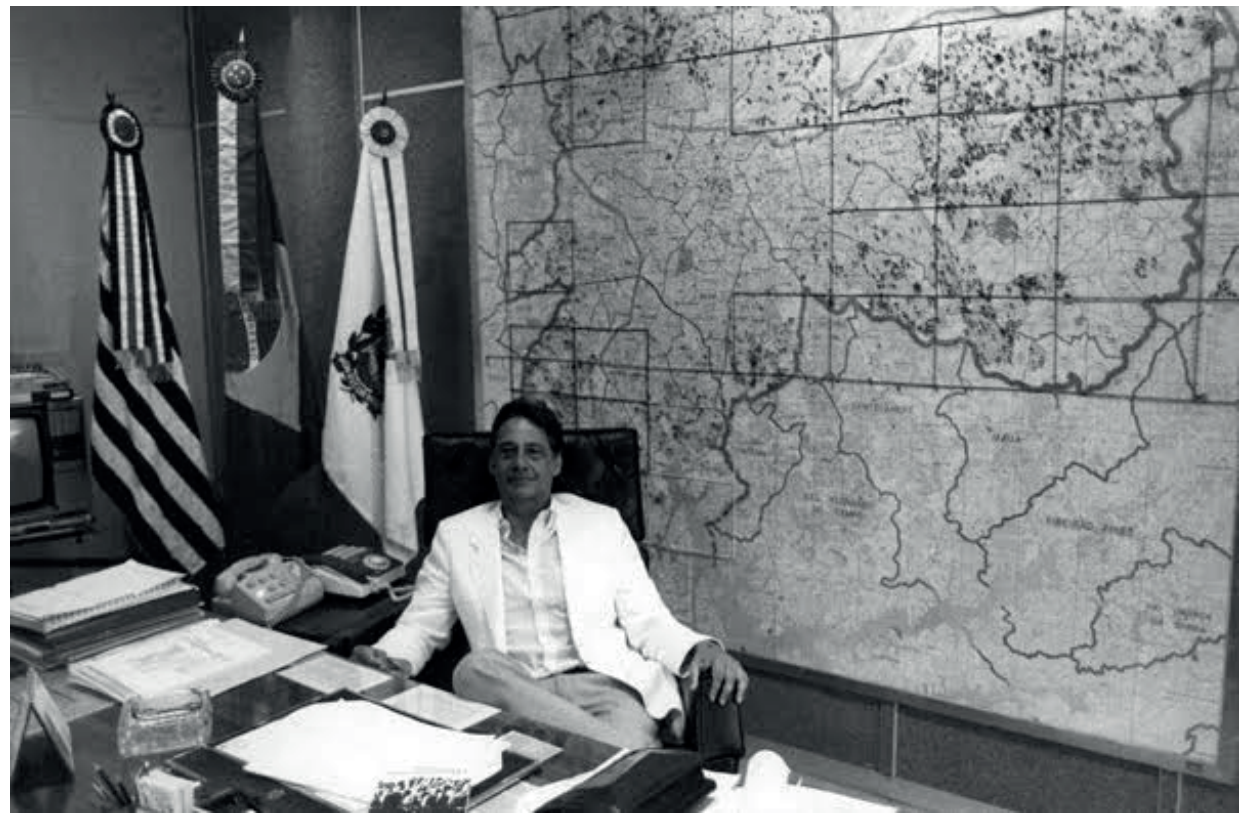

Fonte: http://acervo.estadao.com.br/noticias/acervo,janio-desinfetou-cadeira-que-fhc-sentou-,8805,0.htm.

Jânio Quadros, que se tornou vencedor da eleição municipal contra expectativas geradas por pesquisas de intenção de voto, tomou a foto de Fernando Henrique como mote de uma ação política. Ele "se deixou” fotografar desinfetando a cadeira precocemente utilizada por quem acabou derrotado (Figura 5, cuja autoria não foi identificada, sendo atribuída em diversas páginas da internet ao “Acervo Estadão). 


\section{Figura 5 -}

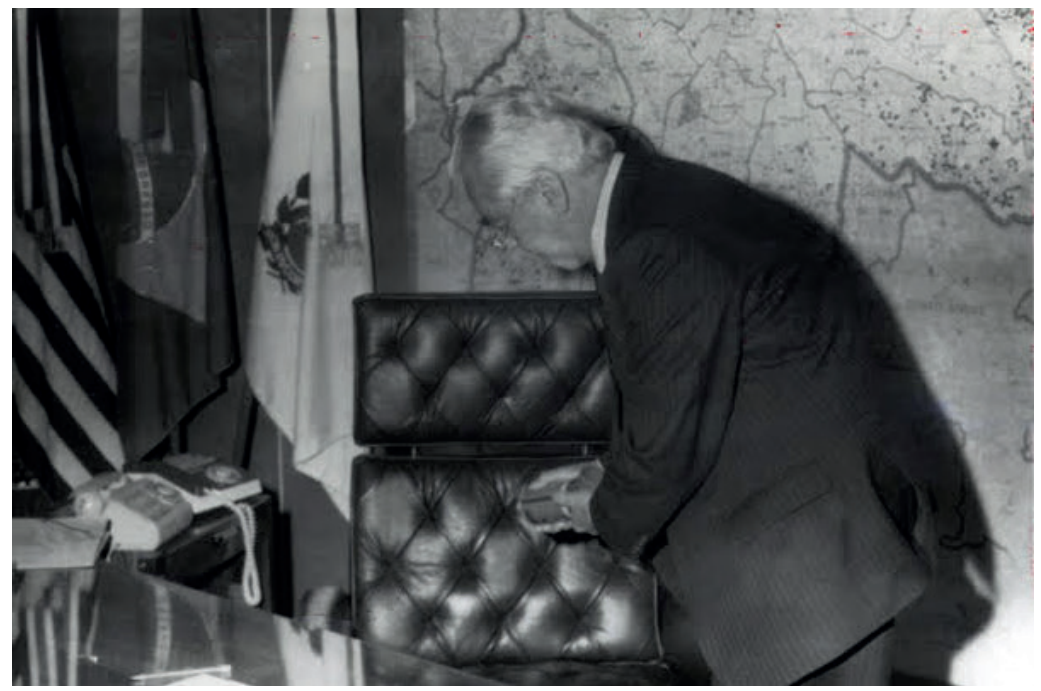

Fonte: http://www.osarrafo.com.br/v1/2016/09/15/contando-com-o-ovo-no-fiofo-da-galinha/.

Se na campanha presidencial dos anos 1960 Jânio Quadros utilizou a vassoura como símbolo da varredura da corrupção e de outras mazelas brasileiras, em 1985 a desinfecção foi com inseticida, metáfora para uma limpeza mais drástica, posto que utilizado contra seres associados a abjeção, como baratas, por exemplo. De qualquer modo, a desinfecção naquele momento não era genérica, mas específica, portanto, também permitindo o sentido de que era necessário livrar a cadeira de eventuais pestilências deixadas por alguém que nela sentou indevidamente.

Uma diversidade de outras fotografias jornalísticas, vencedoras ou não do Prêmio Esso ou de outras premiações, bem como aquelas resultantes de poses combinadas, poderiam ser acionadas como exemplares de relações do mundo político com o jornalismo. A composição desse repertório, desse “museu imaginário”, não é “natural” ou “óbvia”, pois depende de uma ação interessada em estabelecer significações e referências, seja por parte de quem se encontra diante dos desafios de uma pesquisa ou de qualquer outra pessoa envolvida na atividade de leitura (VAZ, 2010, VAZ; BIONDI; 2016, VAZ; VALLE, 2017). Ao deslocarmos nosso olhar, da página para uma potencial série fotográfica, não apenas nos reposicionamos quanto às relações entre fotografias jornalísticas e as imbricações com a política e suas personagens, como também materializamos possibilidades de sentido diversas.

Da mesma forma, as relações temporais que perpassam a fotografia nos nossos esforços de contextualização também se modificam. No breve movimento intertextual que realizamos, buscamos evidenciar, além das relações históricas entre narrativa jornalística e momentos políticos cruciais na história brasileira, as possibilidades múltiplas de leituras 
em que temporalidades e contextos adquirem complexidade para além do supostamente aparente. São essas possibilidades amplas de leitura, de referencialização e significação (de contextualização, em suma) que fotografias que se tornaram paradigmáticas de momentos históricos decisivos para as relações políticas brasileiras oferecem, espraiando sentidos para além do tempo específico de suas produções.

\section{Outras contextualizações: o conservadorismo a assombrar}

Ao retomarmos, num dado momento histórico, a imagem fotográfica publicada em 2012, um outro deslocamento de olhar se faz. Não se trata mais apenas de observar a fotografia nos tempos e nos espaços da página em que circulou inicialmente, nem de remontar uma série histórica de imagens fotojornalísticas de políticos brasileiros. Ao nos posicionarmos nesse presente histórico, a foto também se desloca temporalmente, talvez de modo ainda mais complexo. Afinal, ela pode tornar simultâneas relações temporais heterogêneas, numa composição em que passados, presentes e futuros de qualidades diversas se mesclam. Nos limites deste artigo, apresentamos brevemente duas perspectivas em que essa mescla se faz reconhecível.

Militante contra o regime ditatorial civil-militar que governou o Brasil após o golpe de 1964, Dilma Rousseff foi não somente a primeira mulher a ocupar a presidência do Brasil, mas também uma política de esquerda presa e torturada por aquela ditadura, o que provocou a oposição a ela por amplos setores políticos brasileiros conservadores. A imagem fotográfica que sugere a possibilidade de uma espada atravessando o corpo da presidenta, diante dessa referência histórica, adquire contornos perversos. Menos que referir-se a uma homenagem ou a um evento típico da rotina do cargo presidencial, no presente histórico da publicação e da formatura na Academia das Agulhas Negras, a foto pode ser então lida como uma alusão metafórica à eliminação física promovida pelos militares contra mulheres e homens que combateram a ditadura (GREEN, 2018) e da qual a presidenta escapou.

É importante lembrar que cartazes exibidos durante os protestos pelo impeachment de Dilma Rousseff - cujas possibilidades estão insinuadas no “descontentamento e na desconfiança” do PMDB informados no texto da página que analisamos - lamentavam que ela não tivesse sido assassinada pelos militares, assim como diversos outros cartazes clamavam pela volta dos militares ao poder. Na votação do impedimento pela Câmara Federal, o então deputado Jair Bolsonaro dedicou seu voto ao coronel Brilhante Ustra, notório torturador, que seria, em suas palavras, “o pavor de Dilma Rousseff”. Os ecos de posturas saudosistas da ditadura civil-militar que durou de 1964 a 1985 se materializam, desse modo, naquela fotografia, trazendo à tona um passado que teima em assombrar a sociedade brasileira, que desde a independência formal de Portugal vem convivendo intercaladamente com períodos democráticos e outros autoritários, sob comando civil ou militar. 
Do ponto de vista das articulações políticas, o texto jornalístico informa sobre o descontentamento de um partido político historicamente atrelado ao poder, inclusive na condição de “oposição consentida” ao regime ditatorial de 1964 (GREEN, 2018), sob a denominação anterior, recentemente readquirida, de MDB. Ainda que importante para um tipo de oposição à ditadura civil-militar, o MDB, em sistema bipartidário, acabou por legitimar o banimento de todos os demais partidos, de qualquer matiz ideológico, motivo inclusive para que tenha aglutinado pessoas que em condições democráticas estariam filiadas a outras agremiações partidárias. Não é por acaso, portanto, que a narrativa jornalística sobre o descontentamento e a desconfiança em relação à presidenta Dilma Rousseff destaca senadores do PMDB que se situariam como dissidentes, indicativo da diversidade de posições políticas no interior do partido.

Mas se a página, em seu encaixe de textualidades, insinua um passado que assombra, ele não estaria somente na ameaça de um poder militar, mas também permite remeter às tensões que caracterizam o cenário político brasileiro desde o fim da ditadura civil-militar. De 1985 até 2019, por meio de composições com partidos tão distintos quanto o PSDB (importante lembrar que fundado por dissidentes do PMDB) e o PT, ou pelo golpe travestido de impeachment legítimo contra Dilma Rousseff (CARVALHO, 2019), o PMDB esteve em todos os governos, ocupando ministérios e outros postos estratégicos. As movimentações de descontentamento do PMDB, se não resultaram em candidatura própria à presidência em 2014, vencida por Dilma Rousseff tendo como vice Michel Temer, acabaram por culminar nas articulações que resultaram no impeachment, fazendo com que o PMDB voltasse formalmente a ocupar o Palácio do Planalto.

A quem pertence, então, a mão que empunha a espada que atravessa Dilma Roussef? Ao PMDB, aos militares hoje no poder? Qualquer que seja a resposta, a fotografia adquire um caráter premonitório, de antecipar, em 2012, um conjunto de acontecimentos que levaram à queda de Dilma Roussef e à ascensão desses outros grupos ao poder. O assombro, diante dessa premonição, não vem só do passado, da alusão à ditadura civil-militar, mas também do futuro projetado pela imagem fotográfica, e que no momento atual constitui nosso ontem e nosso hoje.

Numa outra chave de leitura - de contextualização - a fotografia publicada no $O$ Estado de S. Paulo em 21 de agosto de 2012 pode ser vista como a materialização (metonímica ou metafórica) de posicionamentos culturais machistas e misóginos. Afinal, ela sugere uma mulher que se curva sob o jugo da espada (símbolo “masculino” por excelência) empunhada por um homem. Desse modo, essa mesma imagem fotográfica é capaz de acionar uma outra rede contextual que diz respeito à misoginia e à maneira pela qual esse "desejo de extinção" se materializou em outras imagens, não só de Dilma, mas de outras presidentas na América do Sul, a exemplo de Cristina Kirchner, da Argentina. 
Figura 6 -
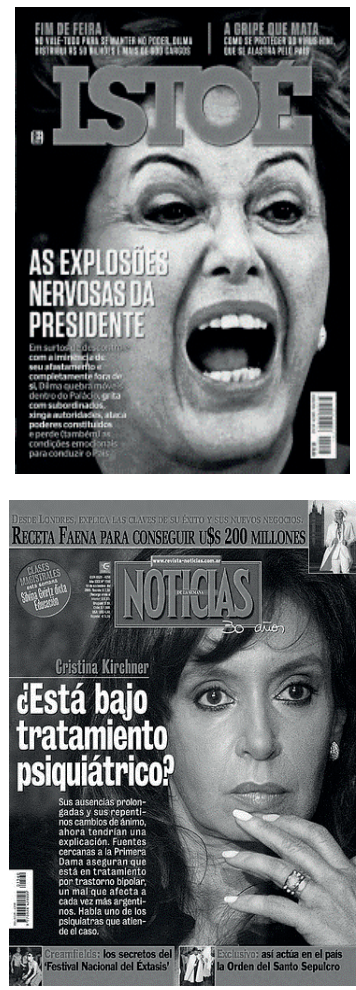
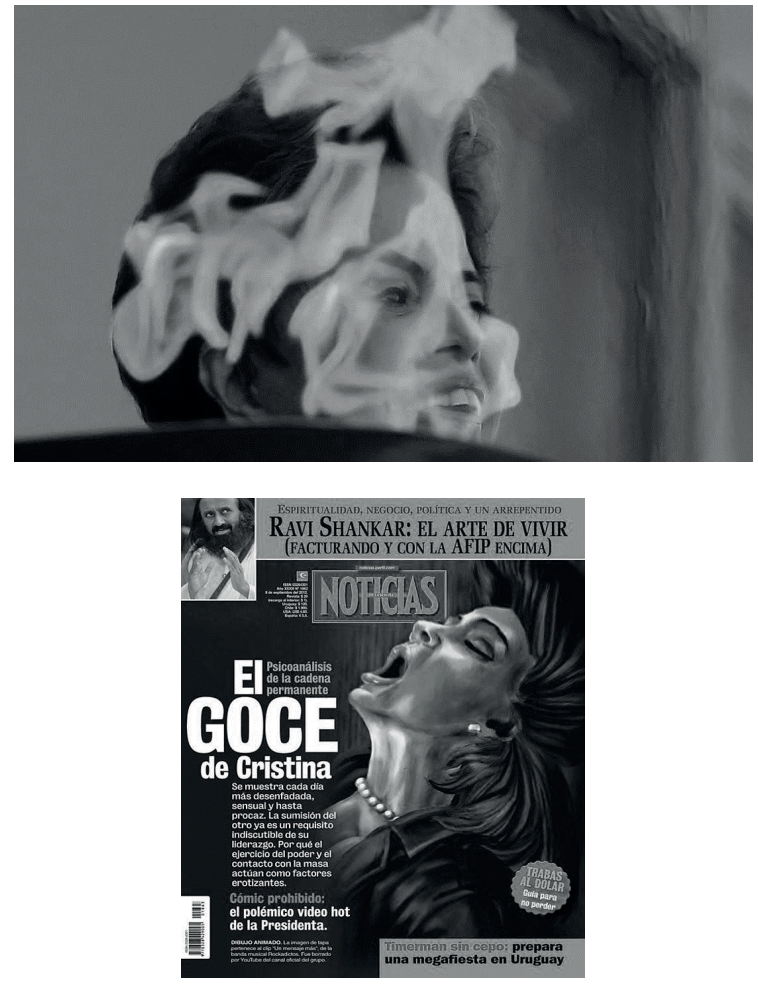

Fonte: https://www.istoe.com.br; https://www.revista-noticias.com.ar.

Como podemos perceber no conjunto imagético da Figura 6, composto por fotos flagrantes ou editadas e uma ilustração, é recorrente o acionar imaginário de uma "queima às bruxas” ou da suspeição da capacidade racional das mulheres na condução do poder. Nessa perspectiva, outros são os assombros, outros passados, futuros e presentes são convocados, outro feixe de relações - temporais, mas não só - se dão a ver.

\section{Algumas considerações}

A abertura contextual que propomos para e a partir da página do jornal O Estado de $S$. Paulo se vale também das contribuições de Gonzalo Abril acerca dos riscos do imanentismo em visadas semióticas, considerando que as textualidades implicam complexos jogos de visualidade e de visibilidades/invisibilidades. Segundo Abril,

Cualquier texto remite efectivamente a uno o varios universos de significado, es decir, a un conjunto de representaciones sobre el mundo, la historia o 
las relaciones sociales, que constituyen conjuntos de categorías (campos conceptuales), imágenes (figuras estéticas, tópicas sentimentales, imaginarios, etc.), y un sinfín de tipificaciones. Pero además, los universos de significado se articulan a un nivel más profundo, el simbólico, que implica ya no sólo la producción y circulación de significados, sino también relación, vínculo y mediación. Un universo simbólico desempeña la función de una estructura profunda para los universos de significado de una sociedad: es el nivel que sustenta sus cosmologías y mitologías, las representaciones compartidas del tiempo y el espacio, los marcos categoriales básicos, los símbolos de la identidad colectiva que rigen las asignaciones del sentido de lo propio/ajeno. (ABRIL, 2009, p. 137-138).

Tomada como um conjunto que pode fazer sentido em função da informação jornalística, assim como das informações publicitárias, a página do jornal oferece pistas valiosas sobre imaginários e símbolos políticos e culturais brasileiros. Trata-se de um texto verbovisual que possibilita transitar por temporalidades distintas, em consonância com a perspectiva de contextualização que adotamos. No exercício metodológico que propomos, as instabilidades do "texto", do "contexto" e do "olhar” (dos pesquisadores, nesse caso) não se apresentam como algo indesejável ou a ser superado num gesto de conhecimento que estabiliza sentidos e relações. Ao contrário, são essas instabilidades que permitem o vigor de leituras, de relações de sentido, de produção de conhecimento.

Nesse sentido, parece-nos urgente a necessidade de incorporarmos esse gesto metodológico na análise jornalística como uma forma de apreender, de maneira menos imanente e mais produtiva, as relações temporais complexas que as narrativas jornalísticas engendram. “Contextualizar”, portanto, mostra-se como um desafio produtivo, uma tarefa necessariamente difícil, uma vez que implica a articulação de relações diversas para a proposição de sentidos, significados e referências. Trata-se de uma operação, de um agir, cujo resultado produz um entendimento plausível, um saber em trânsito, mas jamais a estabilização do mundo.

Em outros termos, pensar as textualidades jornalísticas a partir de noções como contexto e temporalidades coloca em xeque uma série de pressupostos das denominadas teorias do jornalismo que se apegam a princípios explicativos com pretensões à universalidade a-histórica e não contextual. Critérios de noticiabilidade, valores-notícia, agendamento, ação de gatekeepers, dentre outros “mantras” repetidos à exaustão podem, sob inspiração das noções de contexto e temporalidades, passar por revisões teóricas e metodológicas mais refinadas que indiquem suas fragilidades heurísticas e mesmo impertinência de utilização para determinados fenômenos jornalísticos sob investigação.

Como buscamos evidenciar na análise empreendida, compreender as textualidades polissêmicas de uma única página de jornal impresso a partir das potencialidades metodológicas da noção de contexto requer abrir-se a uma multiplicidade de sentidos e de 
leituras de mundo. Tal gesto convida também ao empreendimento de análises intertextuais, convocando relações no interior da página, mas também fora dela. Desse modo, outras fotografias foram fundamentais para a compreensão de lógicas de sentido em fotografias jornalísticas que têm personagens políticas como foco. Elas são, simultaneamente, situadas em contextos específicos e produtoras dos seus próprios contextos, no jogo de temporalidades em que passados, presentes e futuros se mesclam.

Se as fotografias e ilustrações de presidentas testemunham Dilma Rousseff e Cristina Kirchner como algumas das primeiras e poucas mulheres eleitas para a presidência de seus países na América Latina, indicando frágeis avanços políticos e culturais, elas são testemunhas mais veementes do machismo e da misoginia que persistem. Nesse sentido, o jornalismo auxilia na compreensão dessas dinâmicas sexistas, sendo ele próprio elemento perpetuador delas. Em outros termos, nos marcos aqui explorados da noção de contexto, jornalismo, machismo e misoginia são, simultaneamente, explicáveis por relações contextuais e produtores dessas mesmas relações, configurando um dentro e um fora, passado, presente e futuro como tramas cujas complexidades são desafiadoras.

\section{Agradecimentos}

As pesquisas que permitiram a produção deste artigo são financiadas pela Fundação de Amparo à Pesquisa de Minas Gerais (Fapemig), pelo Conselho Nacional de Desenvolvimento Científico e Tecnológico (CNPq), pela Coordenação de Aperfeiçoamento de Pessoal de Nível Superior (Capes) e pela Pró-reitoria de Pesquisa da UFMG.

\section{Referências}

ABRIL, G . Se puede hacer semiótica y no morir de inmanentismo? Revista Científica de Información y Comunicación. 2009, 6. p. 127-147.

BARBOSA, M. C.; REGO, A. R . Historicidade e Contexto em perspectiva Histórica e Comunicacional. Revista Famecos (PUC-RS), v. 24, p. 26989-26989, 2017.

CARVALHO, C. A . Narrativas sobre o golpe no Brasil: acontecimento, jornalismo e disputas de sentido. Revista E-Compós, v. 22, 2019.

FINK, K.; SCHUDSON, M. The rise of contextual journalism, 1950s-2000s. Journalism, 2014, v. 15, n. 1, p. 3-20.

GREEN, J. N. Revolucionário e gay: a vida extraordinária de Herbert Daniel pioneiro na luta pela democracia, diversidade e inclusão. Rio de Janeiro: Civilização Brasileira, 2018.

JÁCOME, P.; FERREIRA, T.; MANNA, N . Recontextualizações do -Ismo: Disputas em torno do jornalismo 'em crise'. Revista Famecos (PUC-RS), v. 24, p. 26991, 2017.

JÁCOME, P. A constituição moderna do jornalismo no Brasil. Curitiba: Appris, 2020.

LEAL, B. S.; JÁCOME, P. As convenções jornalísticas e a verbo-visualidade do jornal impresso em tensionamentos. Revista Intexto (UFRGS), v. 49, p. 123-137, maio/ago. 2020. 
LEAL, B. S.; CARVALHO, C. A . Aproximações à instabilidade temporal do contexto. Revista Famecos (PUC-RS), v. 24, p. 1-17, 2017.

MOURA, M.B. Por uma teoria do formato jornalístico. Belo Horizonte: Selo PPGCOM/UFMG, 2020.

RIBEIRO, A. P. G.; MARTINS, B. G.; ANTUNES, E . Linguagem, sentido e contexto: considerações sobre comunicação e história. Revista Famecos (PUC-RS), v. 24, p. 27047, 2017.

RICOEUR, P . Tempo e narrativa - vol. I: a intriga e a narrativa histórica. São Paulo: Martins Fontes, 2006.

SANTOS, A. C. L . Pequena história do processo de impedimento de Dilma Rousseff: a deposição da presidenta contada a partir de fotografias. Devires (UFMG), v. 13, p. 88-103, 2016.

VAZ, P. B. Cristo revisitado: experiência estética e fotojornalismo. In: LEAL, B. S; GUIMARÃES, C; MENDONÇA, C. M.; (orgs). Entre o sensível e o comunicacional. Belo Horizonte: Autêntica, 2010, p. 189-204.

VAZ, P. B.; BIONDI, A. Silêncio visual e gritos verbais nas narrativas jornalísticas do feminicídio. In: MARTINS, M; CORREA, M. L (orgs). Figurações da morte nos media e na cultura: entre o estranho e o familiar. Braga: Universidade do Minho, 2016, p. 71-86.

VAZ, P. B., VALLE, F. P. Vida e morte nos retratos dos ocupantes do edifício 911. In: MARTINS, M., CORREA, M. L.; VAZ, P. B., ANTUNES, E. (orgs). Sentidos da morte na vida da mídia. Curitiba: Appris, 2017, p. 213-228.

\section{Carlos Alberto Carvalho}

Doutor pelo Programa de Pós-Graduação em Comunicação Social da UFMG, onde é Professor Associado do Curso de Comunicação Social e do Programa de Pós-Graduação em Comunicação Social, na Linha Textualidades Miditiáticas. Suas publicações incluem dezenas de artigos em revistas e livros editados no Brasil e no exterior, abrangendo as temáticas de pesquisa em Jornalismo, Narrativas, Divulgação Científica, Homofobia, Relações de Gênero e Política. É autor dos livros "Visibilidades mediadas nas narrativas jornalísticas - a cobertura da Aids pela Folha de S. Paulo de 1983 a 1987” (São Paulo: Annablume, 2009) e "Jornalismo, homofobia e relações de gênero" (Curitiba: Editora Appris, 2012) e coautor e organizador de livros no Brasil e no exterior. Coordena o Insurgente: Grupo de Pesquisa em Comunicação, Redes Textuais e Relações de Poder/ Saber. É Bolsista de Produtividade em Pesquisa - Nível 2 do CNPq. E-mail: carloscarvalho0209@ gmail.com.

\section{Bruno Souza Leal}

Professor titular do Departamento de Comunicação/Fafich/UFMG e pesquisador permanente do PPGCOM/UFMG, na linha de pesquisa “Textualidades Midiáticas”. Coordena, ao lado de Phellipy Pereira Jácome, o Núcleo de Estudos Tramas Comunicacionais: Narrativa e Experiência, tendo integrado o NUH - Núcleo de Direitos Humanos e Cidadania LGBT da UFMG e os grupos de pesquisa Poéticas da Experiência e Gris/UFMG. Doutor em Estudos Literários pela UFMG. Seus trabalhos compreendem pesquisas sobre jornalismo, narrativa, homocultura, historicidades, televisualidades, gêneros e sexualidades. Tem dezenas de artigos publicados em revistas e livros no Brasil e no 
exterior, sendo autor do livro "Caio Fernando Abreu, a metrópole e a paixão do estrangeiro: contos, identidade e sexualidade em trânsito” (São Paulo: Annablume, 2003), além de outros livros em coautoria ou organização, publicados no Brasil e no exterior. Bolsista de Produtividade em Pesquisa do CNPq E-mail: brunosleal@gmail.com.

\section{Phellipy Pereira Jácome}

Professor do Departamento de Comunicação Social da Universidade Federal de Minas Gerais e Pesquisador Permanente do Programa de Pós-Graduação em Comunicação (PPGCOM/UFMG) na linha Textualidades Midiáticas. Doutor em Comunicação Social pela UFMG. É integrante do Núcleo de Estudos Tramas Comunicacionais: narrativa e experiência. Suas pesquisas compreendem estudos sobre as narrativas midiáticas, a historicidade dos processos comunicacionais, a temporalidade, a referencialidade e a ficção (tendo o jornalismo - em suas diversas textualidades - como principal objeto). Além de dezenas de artigos em revistas e livros brasileiros e estrangeiros, é autor do livro "Fissuras no espelho realista do jornalismo: a narratividade crítica de Barcelona" (Belo Horizonte: PPGCom UFMG, 2015) e “A constituição moderna do jornalismo no Brasil” (Curitiba: Appris, 2020). E-mail: phellipy@ufmg.br.

Recebido em: 30.12.2019

Aprovado em: 01.02.2021

Este artigo é publicado em acesso aberto (Open Access) sob a licença Creative Commons Attribution Non-Commercial (CC-BY-NC), que permite uso, distribuição e reprodução em qualquer meio, sem restrições, desde que sem fins comerciais e que o trabalho original seja corretamente citado. 